\title{
Associations Between Non-Cognitive Skills, Self-Rated Health, Life Style, and Concern About Food in 6-16-Year-Old Japanese Students
}

\author{
Tomoko Osera ${ }^{1,5}$, Mitsuyo Awai ${ }^{2}$, Misako Kobayashi ${ }^{3}$, Setsuko Tsutie ${ }^{4}$ \& Nobutaka Kurihara $^{5}$ \\ ${ }^{1}$ Department of Nutrition and Health Sciences Faculty of Food and Nutritional Sciences, Toyo University, \\ Gunma, Japan \\ ${ }^{2}$ School of Nursing, Kansai University of Nursing and Health Science, Hyogo, Japan \\ ${ }^{3}$ Takakuradai Kindergarten attached to Kobe Women's University, Hyogo, Japan \\ ${ }^{4}$ Clinical Nutrition Management, Graduate School of Home Economics, Kobe Women's University, Hyogo, \\ Japan \\ ${ }^{5}$ Hygiene and Preventive Medicine, Graduate School of Home Economics, Kobe Women's University, Hyogo, \\ Japan
}

Correspondence: Nobutaka Kurihara, 2-1 Higashisuma-Aoyama, Suma, Kobe 654-8585, Japan. Tel: 81-78-737-2417. E-mail: kurihara@suma.kobe-wu.ac.jp

Received: March 26, 2019 Accepted: June 25, 2019 Online Published: July 3, 2019

doi:10.5539/jedp.v9n2p26 URL: http://doi.org/10.5539/jedp.v9n2p26

\begin{abstract}
Little is known about the effects of the non-cognitive skills on health. In this study, questionnaires were distributed to 1,658 school children aged 6-16 years and their parents in Hyogo Prefecture in Japan, who completed them at home and returned them in Freepost envelopes. The questionnaires included items about the child and his/her self-rated health (SRH), lifestyle, food-related habits and attitudes. The responses were anonymous and unidentifiable. Associations between the independent variables and high/low non-cognitive skills were assessed with the $\chi^{2}$ test or Fisher's exact test at a $5 \%$ level of significance. Groups with high and low non-cognitive skills were defined and factors that differed significantly between them were examined using logistic regression analysis. In total, 496 (29.9\%) returned both completed questionnaires. In this study, we separated the children and students aged 6-12 and 13-16 years, respectively. Furthermore, we categorized them according to the Japanese education system. Among the children aged 6-12 years, the high non-cognitive skills group suffered fewer headaches, went to bed earlier, had a greater preference for home-cooked meals, and had better exercise habits compared with the low non-cognitive skills group. In the students aged 13-16 years, the high non-cognitive skills group experienced fewer headaches, went to bed earlier, had a greater preference for home-cooked meals, and had better exercise habits compared with the low non-cognitive skills group. In conclusion, the findings of this study suggested that a high level of non-cognitive skills was associated with high SRH and greater concern about food.
\end{abstract}

Keywords: non-cognitive skills, self-rated health, adolescents

\section{Introduction}

Economists have focused on non-cognitive skills in education (Heckman et al., 2006; Bowles et al., 2001), and the Organisation for Economic Co-operation and Development (OECD) has promoted education based on non-cognitive skills (OECD, 2015). The development of non-cognitive skills during early childhood are of great importance and benefit for later life (OECD, 2015). However, non-cognitive skills have not been defined in detail (Heckman, 2007; Farkas, 2003).

Little is known about the effects of non-cognitive skills on health. High-quality, intensive interventions during childhood can be effective in preventing, or at least delaying, the onset of various diseases in adulthood and in promoting health (Campbell et al., 2014). Thus, lifestyle during early childhood can be of great importance for a child's future health. It has also been suggested that non-cognitive skills are likely to affect good health behaviours (Heckman, 2007; Chiteji, 2010). In addition, associations between non-cognitive skills and mental health and income have been reported (Cuesta \& Budria, 2015). Sanchez focused on the role of early nutrition and found that improvements in height during the first year of life have an effect on cognitive and non-cognitive skills (Sanchez, 2017). These findings show that non-cognitive skills are related to several known factors. According to the 
previous study, we defined the following: narcissism, patriotism, curiosity, motivation to learn and social norm. In Japan, some researchers describe a non-cognitive skill as a force that involves the society.

Self-rated health (SRH) is good predictor of health condition. Adolescents' mental health is a major public health issue. SRH provides a way to measure an adolescent's quality of life (Zullig et al., 2005), and it has been reported that SRH was associated with lifestyle and psychological factors (Sharma et al., 2016; Vigins et al., 2002). SRH is also related to some factors considered to be non-cognitive skills.

This raises the question of whether there is a relationship between non-cognitive skills and SRH. If there is, both could be increased for young people's health awareness. In addition, the relationships between non-cognitive skills and lifestyle and attitudes towards food are not well known. In this study, we have attempted to clarify these relationships. The purpose of this study was to investigate the factors that predict the non-cognitive skills of young school children and junior high school students in Japan.

\section{Method}

\subsection{Sample}

This cross-sectional study was conducted from June to September 2017. Questionnaires were distributed to 1,658 school children aged 6-16 years in rural and urban areas in Hyogo Prefecture, Japan. Each child received two questionnaires, one for the child and one for the guardians; the child and guardians completed these at home and returned them in a Freepost envelope. This provided a convenient method for obtaining the information. In addition, we suggested that the 6-9-year-old children answer the questionnaire with their guardians.

\subsection{Definition of Non-cognitive Skills}

Heckman (2007) and Farkas (2003) describe types of non-cognitive skills and provide further discussion of the terminology. Non-cognitive skills described in the literature include personal efficacy, time preference or orientation towards the future, self-esteem, locus of control, level of application, the ability to pay attention, the ability to work with other, organisation skills, self-regulation, motivation, adventurousness, self-control, and conscientiousness. Mischel founded from the research programmes who reviewed specify some of the cognitive processes that underlie this type of delay of gratification in early life (Mischel et al., 1989).

For this study, we chose five aspects of non-cognitive skills: narcissism, patriotism, curiosity, motivation to learn, and compliance with social norms. These took into consideration Japanese culture and Japan's education system. They are summarised in Table 1 (OECD, 2015).

\subsection{Questionnaire Items}

The questionnaire consisted of items about SRH, lifestyle (e.g., wake-up time), the child's undiagnosed complaints (e.g., stomach ache), the guardian's SRH, and 36 parameters regarding the child's food-related habits and attitudes. Various global SRH questions were used, such as "How would you rate your overall health?" and the responses were graded on a five-point scale (i.e. excellent, very good, good, fair, and poor) (Joffer et al., 2016; Warnoff et al., 2016; Wu et al., 2013).

In detail, the questionnaire comprised items on the child's SRH, the guardian's SRH, three demographic characteristics, four lifestyle parameters (wake-up time, bedtime, and sleeping habits), five miscellaneous health-related parameters (e.g., tiredness, anorexia, dizziness, irritability and cephalalgia), five parameters related to Breslow's seven healthy habits, excluding alcohol consumption and smoking habit (Breslow \& Enstrom, 1980), and 15 parameters related to food-related habits and attitudes (e.g., frequency of eating breakfast, food-related concerns, respect for food, watching TV while eating, and talking about food with the family). The parameters included in the questionnaire were based on results of our previous studies (Osera et al., 2017). Appendix 1 provides a description of all the measures included in the analysis. Both 4- and 5-point rating scales were used, with higher scores indicating more positive food habits. For example, questions regarding 'respect for food' utilised a 5 -point rating scale $(5=$ high concern, $4=$ moderate concern, $3=$ concern, $2=$ little concern, and $1=$ no concern). 
Table 1. Distribution of responses to the five non-cognitive skills items in the two age groups

\begin{tabular}{|c|c|c|c|c|c|}
\hline & \multicolumn{2}{|c|}{ Age 6-12 years } & \multicolumn{2}{|c|}{ 13-16 years } & \multirow{2}{*}{ P value } \\
\hline & $\mathrm{N}$ & $\%$ & $\mathrm{~N}$ & $\%$ & \\
\hline \multicolumn{6}{|l|}{ Narcissism } \\
\hline Excellent & 98 & 33.8 & 37 & 18.1 & \\
\hline Very good & 111 & 38.3 & 56 & 27.5 & \\
\hline Good & 60 & 20.7 & 79 & 38.7 & $<0.001 * * *$ \\
\hline Fair & 14 & 4.8 & 22 & 10.8 & \\
\hline Poor & 7 & 2.4 & 10 & 4.9 & \\
\hline \multicolumn{6}{|l|}{ Patriotism } \\
\hline Excellent & 170 & 58.6 & 112 & 54.9 & \\
\hline Very good & 86 & 29.7 & 70 & 34.3 & \\
\hline Good & 26 & 9.0 & 17 & 8.3 & N.S. \\
\hline Fair & 6 & 2.1 & 4 & 2.0 & \\
\hline Poor & 2 & 0.7 & 1 & 0.5 & \\
\hline \multicolumn{6}{|l|}{ Curiosity } \\
\hline Excellent & 142 & 49.0 & 83 & 40.7 & \\
\hline Very good & 72 & 24.8 & 67 & 32.8 & \\
\hline Good & 21 & 7.2 & 18 & 8.8 & N.S. \\
\hline Fair & 28 & 9.7 & 18 & 8.8 & \\
\hline Poor & 27 & 9.3 & 18 & 8.8 & \\
\hline \multicolumn{6}{|l|}{ Motivation to learn } \\
\hline Excellent & 94 & 32.5 & 63 & 30.9 & \\
\hline Very good & 115 & 39.8 & 67 & 32.8 & \\
\hline Good & 46 & 15.9 & 41 & 20.1 & N.S. \\
\hline Fair & 25 & 8.7 & 22 & 10.8 & \\
\hline Poor & 9 & 3.1 & 11 & 5.4 & \\
\hline \multicolumn{6}{|l|}{ Social norms } \\
\hline Excellent & 258 & 89.6 & 178 & 87.3 & \\
\hline Very good & 27 & 9.4 & 21 & 10.3 & N.S. \\
\hline Good & 3 & 1.0 & 5 & 2.5 & \\
\hline Fair & - & & - & & \\
\hline Poor & - & & - & & \\
\hline \multicolumn{6}{|c|}{ Non-cognitive skills +} \\
\hline High & 141 & 48.6 & 79 & 38.7 & $<0.05^{*}$ \\
\hline Low & 149 & 51.4 & 125 & 61.3 & \\
\hline
\end{tabular}

Note. Significant differences between the age groups at ${ }^{*} \mathrm{p}<0.05 ; * * \mathrm{p}<0.01 ; * * \mathrm{p}<0.001$.

+ Children were assigned to the high and low non-cognitive skills groups according to whether their total scores for the five items were above or below the median value of 21 points.

\subsection{Statistical Analysis}

We totalled the scores for these five items and divided the subjects into high and low non-cognitive skill groups 
according to the median value (21 points). High and low non-cognitive skills groups were identified and differences between them were examined for all significant items using a logistic regression analysis after adjusting for sex and age. A dichotomous logistic regression analysis was performed with the variables that were significant in the bivariate analysis entered stepwise into the analysis. A Hosmer-Lemeshow test was applied to determine the model's goodness-of-fit. Data were analysed using SPSS for Windows, version 25.0 (IBM Corp., Armonk, NY, USA).

\subsection{Ethics Statement}

The children and their guardians were fully informed about the objectives and methods of this study and voluntarily answered the questionnaire without any compulsion and with the understanding that they could withdraw at any time. Individual privacy was strictly protected throughout the investigation. Signed consent was obtained from the guardians of each child. This study was approved by the Kobe Women's University Ethics Committee regarding Human Subjects (approval number H29-1).

\section{Results}

\subsection{Summary of Responses About the Five Components of Non-cognitive Skills}

Table 1 shows the distributions of responses for the five components of non-cognitive skills in two age groups (612 years and 13-16 years). There were no significant differences between the age groups for patriotism, curiosity, motivation to learn or compliance with social norms, but the mean narcissism score was higher in the yonger age group $(\mathrm{p}<0.001)$. We totalled the scores for these five items and divided the subjects into high and low non-cognitive skill groups according to the median value (21 points). However, there were significant differences in the number of high and low non-cognitive skill subjects between the age groups $(p<0.05)$, so the subsequent analysis considered the age groups separately.

\subsection{Sample Characteristics and Item-Specific Responses}

Table 2 shows the distributions of responses to some questionnaire parameters and sample characteristics by age group and high or low non-cognitive skills group. Of the 1220 pairs of questionnaires distributed to children in the 6-12 year age group, both completed questionnaires were returned for $292(23.9 \%)$ of the children $(43.4 \%$ boys and $56.6 \%$ girls; $\mathrm{P}=$ N.S.). Similarly, completed questionnaires were received for 204 (46.6\%) of 438 students in the $13-16$ year age group ( $48.0 \%$ boys and $52.0 \%$ girls; $\mathrm{P}=$ N.S.).

\subsection{Relationships Between Non-cognitive Skills and SRH, Lifestyle and Food Habits}

The results suggested that positive SRH and food concerns were associated with high non-cognitive skills. In the 6-12 year age group, 10 factors were significantly associated with non-cognitive skills (Table 2). Three of these were shown to be significant factors in the logistic regression analysis as the details in Table 2 . The other seven factors showing statistically significant relationships with high or low non-cognitive skills were the guardian's $\mathrm{SRH}$, helping to set the table, talking with the family during dinner, discussing taste with the family during dinner, food preferences, respect for food, and liking school lunch ( $\mathrm{p}<0.05$ by Fisher's exact test, data not shown). In the 13-16 year age group, 10 factors were significantly associated with high or low non-cognitive skills. Four of these were shown to be significant factors in the logistic regression analysis as shown in the detail (Table 2). The other six factors showing significant relationships with high and low non-cognitive skills were helping to set the table, talking with the family during dinner, discussing taste with the family during dinner, watching TV while eating, memories of home meals during childhood, and maintaining an ideal body weight ( $\mathrm{p}<0.05$ by Fisher's exact test, data not shown). 
Table 2. Distribution of Questionnaire Responses According to Age Group and High or Low Non-cognitive Skills Group

\begin{tabular}{|c|c|c|c|c|c|c|c|c|c|c|c|}
\hline \multirow{3}{*}{ Variables } & & \multicolumn{4}{|c|}{ Age 6-12 years } & \multirow{3}{*}{$P$ value } & \multicolumn{4}{|c|}{ 13-16 years } & \multirow{3}{*}{$\mathrm{P}$ value } \\
\hline & & \multicolumn{2}{|c|}{ High } & \multicolumn{2}{|c|}{ Low } & & \multicolumn{2}{|c|}{ High } & \multicolumn{2}{|c|}{ Low } & \\
\hline & & $\mathrm{N}$ & $\%$ & $\mathrm{~N}$ & $\%$ & & $\mathrm{~N}$ & $\%$ & $\mathrm{~N}$ & $\%$ & \\
\hline \multicolumn{12}{|l|}{ Sex } \\
\hline & Boy & 64 & 50.8 & 77 & 47.0 & N.S. & 39 & 50.0 & 58 & 46.8 & N.S. \\
\hline & Girl & 62 & 49.2 & 87 & 53.0 & & 39 & 50.0 & 66 & 53.2 & \\
\hline \multicolumn{12}{|l|}{ Grade $^{*+}$} \\
\hline & Grade 1 & 60 & 56.1 & 47 & 43.9 & & 23 & 29.1 & 32 & 25.6 & \\
\hline & Grade 2 & 42 & 43.3 & 55 & 56.7 & N.S. ${ }^{\$}$ & 19 & 24.1 & 34 & 27.2 & N.S. $\$$ \\
\hline & Grade 3 & 39 & 44.8 & 47 & 54.0 & & 37 & 46.8 & 59 & 47.2 & \\
\hline \multicolumn{12}{|l|}{ SRH } \\
\hline & Excellent & 117 & 84.4 & 93 & 64.6 & & 57 & 73.1 & 52 & 41.9 & \\
\hline & Very good & 19 & 13.8 & 42 & 29.2 & & 17 & 21.8 & 58 & 46.8 & \\
\hline & Good & 1 & 0.7 & 8 & 5.6 & $<0.001$ & 2 & 2.6 & 11 & 8.9 & $<0.001^{* * *}$ \\
\hline & Fair & 1 & 0.7 & 1 & 0.7 & & 2 & 2.6 & 2 & 1.6 & \\
\hline & Poor & - & & - & & & 0 & 0 & 1 & 0.8 & \\
\hline \multicolumn{12}{|c|}{ Concern about food } \\
\hline & High & 61 & 43.3 & 23 & 15.4 & & 42 & 53.2 & 35 & 28.5 & \\
\hline & Considerable & 52 & 36.9 & 69 & 46.3 & & 22 & 27.8 & 49 & 39.8 & \\
\hline & Medium & 16 & 11.3 & 30 & 20.1 & $<0.001$ & 11 & 13.9 & 27 & 22.0 & $<0.01 * *$ \\
\hline & Low & 9 & 6.4 & 19 & 12.8 & & 4 & 5.1 & 7 & 5.7 & \\
\hline & None & 3 & 2.1 & 8 & 5.4 & & 0 & 0 & 5 & 4.1 & \\
\hline \multicolumn{12}{|c|}{ Liking for home meals } \\
\hline & Very much & 115 & 81.6 & 66 & 44.3 & & 62 & 78.5 & 68 & 55.3 & \\
\hline & A lot & 23 & 16.3 & 68 & 45.6 & & 14 & 17.7 & 41 & 33.3 & \\
\hline & Moderately & 2 & 1.4 & 13 & 8.7 & $<0.001$ & 2 & 2.5 & 11 & 8.9 & $<0.01 * *$ \\
\hline & Not much & 1 & 0.7 & 1 & 0.7 & & 0 & 0 & 3 & 2.4 & \\
\hline & Dislike & 0 & 0 & 1 & 0.7 & & 1 & 1.3 & 0 & 0 & \\
\hline \multicolumn{12}{|c|}{ Feeling irritated $^{++}$} \\
\hline & Never & - & & - & & & 7 & 8.9 & 5 & 4 & \\
\hline & Often & - & & - & & & 19 & 24.1 & 19 & 15.2 & \\
\hline & Sometimes & - & & - & & & 9 & 11.4 & 21 & 16.8 & $<0.05^{*}$ \\
\hline & Rarely & - & & - & & & 33 & 41.8 & 42 & 33.6 & \\
\hline & Usually & - & & - & & & 11 & 13.9 & 38 & 30.4 & \\
\hline
\end{tabular}

SRH, self-rated health.

* Grade 1, 7 and 8 years; Grade 2, 9 and 10 years; Grade 3,11 and 12 years.

+ Grade 1, 13 years; Grade 2, 14 years; Grade 3, 15 and 16 years.

$\$$ Significant difference was not combined.

++ Only the 13-16 year age group. 


\subsection{Multiple Logistic Regression Analyses}

The results of the logistic regression analysis for the 6-12 year age group showed significant positive associations between being in the high non-cognitive skills group and liking home meals, high SRH, and having concern about food (Table 3). After adjusting for sex and age, the logistic regression analysis showed significant positive associations between being in the high non-cognitive skills group and liking home meals [odds ratio (OR): 3.55; 95\% confidence interval (CI): 2.13-5.90], SRH [OR: 1.66; 95\% CI: 0.99-2.78] and having concern about food [OR: 1.47; 95\% CI: $1.13-1.91]$.

The results of the logistic regression analysis for the 13-16 year age group showed significant positive associations between being in the high non-cognitive skills group and high SRH, having concern about food, and not feeling irritated (Table 4). After adjusting for sex and age, the logistic regression analysis showed significant positive associations between being in the high non-cognitive skills group and SRH [OR: 2.11; 95\% CI: 1.23-3.62], having concern about food [OR: 1.55; 95\% CI: 1.09-2.22], and not feeling irritated [OR: 1.44; 95\% CI: 1.09-1.90].

Table 3. Factors significantly associated with high non-cognitive skills in the 6-12 year age group in multiple regression analysis after covariate adjustment

\begin{tabular}{cccc}
\hline & OR & $(95 \% \mathrm{CI})$ & P value \\
\hline Liking home-cooked meals & 3.54 & $(2.13,5.88)$ & 0.000 \\
High self-rated health & 1.68 & $(1.00,2.81)$ & 0.050 \\
Having concern about food & 1.47 & $(1.13,1.91)$ & 0.004 \\
\hline
\end{tabular}

OR, Odds ratio; CI, confidence interval.

The multiple regression analysis used the stepwise method.

Liking home-cooked meals indicated that the children preferred meals at home.

Table 4. Factors significantly associated with high non-cognitive skills in the 13-16 year age group in multiple regression analysis after covariate adjustment

\begin{tabular}{cccc}
\hline & OR & $(95 \% \mathrm{CI})$ & P value \\
\hline High self-rated health & 2.09 & $(1.22,3.57)$ & 0.007 \\
Having concern about food & 1.56 & $(1.09,2.23)$ & 0.014 \\
No feeling of irritation & 1.42 & $(1.08,1.85)$ & 0.011 \\
\hline
\end{tabular}

OR, Odds ratio; CI, confidence interval.

The multiple regression analysis used a stepwise method.

Having concern about food increased if many students had concern about food increasingly.

\subsection{Relationship Between Non-cognitive Skills and Memories of Meals During Childhood}

Table 5 shows the relationship between non-cognitive skills and the children's memories about meal times during childhood. Those in the high non-cognitive skills groups had better memories than those in the low non-cognitive skills groups ( $\mathrm{p}<0.05$ by Fisher's exact test). 
Table 5. Memory of meal times during childhood by high and low non-cognitive skills group

\begin{tabular}{|c|c|c|c|c|c|}
\hline \multirow{2}{*}{ Variables } & \multicolumn{2}{|c|}{ High } & \multicolumn{2}{|c|}{ Low } & \multirow{2}{*}{ P value } \\
\hline & $\mathrm{N}$ & $\%$ & $\mathrm{~N}$ & $\%$ & \\
\hline \multicolumn{6}{|c|}{ Memories of meal times during childhood } \\
\hline Excellent & 51 & 64.6 & 53 & 43.1 & \multirow{5}{*}{$<0.05^{*}$} \\
\hline Very good & 19 & 24.1 & 42 & 34.1 & \\
\hline Good & 7 & 8.9 & 23 & 18.7 & \\
\hline Fair & 0 & 0 & 2 & 1.6 & \\
\hline Poor & 2 & 2.5 & 3 & 2.4 & \\
\hline \multicolumn{6}{|c|}{ Remembers home meals during childhood } \\
\hline Usually & 41 & 51.9 & 38 & 30.9 & \multirow{5}{*}{$<0.01 * *$} \\
\hline Often & 24 & 30.4 & 32 & 26.0 & \\
\hline Sometimes & 5 & 6.3 & 19 & 15.4 & \\
\hline Rarely & 6 & 7.6 & 27 & 22.0 & \\
\hline Never & 3 & 3.8 & 7 & 5.7 & \\
\hline
\end{tabular}

Significant differences between the high and low non-cognitive skills groups at $* \mathrm{p}<0.05 ; * * \mathrm{p}<0.01 ; * * * \mathrm{p}<0.001$.

\section{Discussion}

It is interesting to note that only the questionnaire responses about narcissism showed a significant difference between the two age groups (Table 1). Junior high school students and high school students in grade 1 find it very difficult to attempt with family, friends, become identity themselves (Tanaka, 1985). So, the percentage of this items rate was slightly down, going up to age group. In addition, the total variable of non-cognitive skills were significantly different between the age groups. This is a useful finding for parents, caregivers and teachers.

The most important finding of this study was that high/low non-cognitive skills were related to SRH scores. Studies of SRH have shown that behavioural factors, including smoking, physical activity and body weight, influenced adolescent SRH (Vigins et al., 2002), and income has also been shown to be an important predictor of SRH (Goodman, 1999). In addition, Japanese students have reported higher SRH than those in Peru and Brazil (Silva et al., 2018; Sharma et al., 2016). Middle-aged Japanese people report lower SRH than younger Japanese people (Park \& Lee, 2012). In addition, mental factors have been shown to have a greater impact on SRH for Japanese people than for Koreans (Park \& Lee, 2012).

This study focused on several factors. The first was the child's concern about food. Our previous study of 35 -year-old children revealed that food preference was related to their concern about food, and this affected their lifestyle (Osera et al., 2016). Another report suggested that concern about food was not related to children's knowledge of nutrition (Spexoto et al., 2015). The results of the present study suggested an association between the level of non-cognitive skills and concern about food. In this way, factors of consciousness may be easy to associate.

Second, feeling irritation is a neurological symptom. Weber et al. (2007) found that subjects who felt irritated showed significantly higher blood pressure and norepinephrine levels than non-irritated subjects and concluded that heightened emotional irritation before stress may be regarded as a psychological risk factor (Weber et al., 2007). Thus, irritation is not good for health. Our study found an association between high/low non-cognitive skills and feeling irritation. This suggested that non-cognitive skills may be affected by a person's health. The junior high school students with high non-cognitive skill may have good dealing with stress.

Third, the results of our previous study of high school students suggested significant associations between SRH and the frequency of eating breakfast and liking home meals, with the results including eating behaviour (Osera et al., 2017). In addition, our previous study of junior high school students suggested that SRH was significantly associated with going to bed early, having good exercise habits, not experiencing headaches and liking home meals (Osera et al., 2019). These results included eating behavior and lifestyle, but the results suggested that SRH may be more closely associated with concern than with actual behaviour. In general, inner thought is a premise factor of behaviour, as is seen, for example, in the Knowledge-Attitude-Behaviour model and the Transtheoretical model. 
Lin et al have suggested that motivation is important, and that nutrition education should therefore not only include information about the serving requirements for the various food groups but should also apply appropriate theories to improve motivation for healthy eating (Lin et al., 2007). Our finding suggested that higher levels of non-cognitive skills are also important for improving SRH. This may be connected with their future health. It is interesting to note that our finding suggested that non-cognitive skills were associated with concern (the inner thought, such as mentality or psychological) rather than with actual behaviours (Tables 3, 4). The logistic regression analysis showed four factors to be significant, all associated with concern (the inner thought) and not with behaviour.

In addition, Table 5 showed that these factors were associated with non-cognitive skills, but their influence was not strong. Similar to liking home meals, childhood memories of eating may also be associated with high non-cognitive skills. These factors did not have a big influence because logistic regression analysis was not selected but there were significant associations between high non-cognitive skills and these two factors of childhood memories. Our previous studies have also suggested that liking home meals and good memories of eating during childhood are important for health; this is connected with Bowlby's secure base theory. Secure base is very important for a child's healthy development (Bucci et al., 2015; Bowlby, 2008; Bretherton, 1992). In addition, Essen and Martensson have suggested more directly that internalised memories related to food that are associated with positive emotions can be used to build resilience by helping young people to adapt and better manage developmental stress (Essen \& Martensson, 2017). Above all, children's good memories are connected with their mother's concern about their children's food habits and lifestyle. We discussed concern about food earlier. Again, concern about food and good memories are important for a child's healthy development. These factors are also associated with high non-cognitive skills.

We would like to use more selecting a larger sample. High non-cognitive skills are useful for a child's SRH and child's SRH are useful for children's health. However, our sample was small. In addition, the questionnaires in this study were collected using Freepost envelopes, the data may have selection bias. In future studies, we would like to search new areas, including those with poverty and people with health problems. Our findings predict in general which Japanese children aged 6-16 years will be healthy. We believe that these findings are of value. More importantly, we need to consider how to improve the children's non-cognitive skills. We believe that the data are useful to the children because the non-cognitive skills are associated with their SRH and lifestyles/food habits. In the next study, we will aim to increase non-cognitive skills of children. We would like to be a clue this study's suggestion.

The results of this study could benefit school children aged 6-16 years. Having high non-cognitive skills was significantly associated with high SRH scores and having concern about food. Thus, non-cognitive skills maybe connected with concern.

\section{Acknowledgments}

We thank all the students, their guardians and the teachers at the schools for their participation and cooperation with our questionnaire.

\section{References}

Bowlby, J. A. (2008). Secure Base: Parent-Child Attachment and Healthy Human Development. New York, NY, USA: Basic Books.

Bowles, S., Gintis, H., \& Osborne, M. (2001). Incentive-Enhancing Preferences: Personality, Behavior, and Earnings. American Economic Review, 91, 155-158. https://doi.org/10.1257/aer.91.2.155

Bretherton, I. (1992). The origins of attachment theory: John Bowlby and Mary Ainsworth. Dev. Psychol., 28, 759-775. https://doi.org/10.1037/0012-1649.28.5.759

Breslow, L., \& Enstrom, J. E. (1980). Persistence of health habits and their relationship to mortality. Preventive Medicine, 9, 469-483. https://doi.org/10.1016/0091-7435(80)90042-0

Bucci, S., Roberts, N. H., Danquah, A. N., \& Berry, K. (2015). Using attachment theory to inform the design and delivery of mental health services: A systematic review of the literature. The British Psychological Society, 88, 1-20. https://doi.org/10.1111/papt.12029

Campbell, F., Conti, G., Heckman, J., Moon, S., Pinto, R., Pungello, E., \& Pan, Y. (2014). Early childhood investments substantially boost adult health. Science, 343, 1478-1485. https://doi.org/10.1126/science.1248429

Chiteji, N. (2010). Time-preference, non-cognitive skills and well-being across the life course: Do non-cognitive 
skills encourage healthy behaviour? American Economic Review, 100, $200-204$. https://doi.org/10.1257/aer.100.2.200

Cuesta, M., \& Budria, S. (2015). Income deprivation and mental well-being: The role of non-cognitive skills. Economics and Human Biology, 17, 16-28. https://doi.org/10.1016/j.ehb.2014.11.004

Essen, E. V., \& Martensson, F. (2017). Young adults' use of emotional food memories to build resilience. Appetite, 112, 210-218. https://doi.org/10.1016/j.appet.2017.01.036https://doi.org/10.1037/10762-000

Farkas, G. (2003). Cognitive skills and noncognitive traits and behaviors in stratification processes. Annu Review of Sociology, 29, 541-562. https://doi.org/10.1146/annurev.soc.29.010202.100023

Fostering Social and Emotional Skills Through Families, Schools and Communities 2015 OECD http://www.oecd.org/education/ceri/FosteringSocialAndEmotionalSkillsJAPANESE.pdf

Goodman, E. (1999). The role of socioeconomic status gradients in explaining differences in US adolescents' health. American Journal of Public Health, 89, 1522-1528.

Heckman, J., Stixrud, J., \& Urzua, S. (2006). The effect of cognitive and noncognitive abilities on labor market outcomes and social behaviour. Journal of Labor Economics, 24, 411-482. https://doi.org/10.1086/504455

Heckman, J. (2007). The economics, technology and neuroscience of human capability formation. Proceedings of the national academy of science (PNAS), 33, 13250-13255. https://doi.org/10.1073/pnas.0701362104

Joffer, J., Jerden, L., Ohman, A., \& Flacking, R. (2016). Exploring self-rated health among adolescents: A think-aloud study. BMC Public Health, 16, 156. https://doi.org/10.1186/s12889-016-2837-z

Lin, W., Yang, H., Hang, C., \& Pan, W. (2007). Nutrition knowledge, attitude, and behaviour of Taiwanese elementary school children. Asia Pacific Journal of Clinical Nutrition. 16, 534-546.

Mischel, W., Shoda, Y., \& Rodriguez, M. L. (1989). Delay of Gratification in Children. Science, 244, $933-938$. https://doi.org/10.1126/science.2658056

Osera, T., Awai, M., Kobayashi, M., Tsutie, S., \& Kurihara, N. (2017). Relationship between self-rated health and lifestyle and food habits in Japanese high school students. Behavioral Sciences, $7,71$. https://doi.org/10.3390/bs7040071

Osera, T., Tsutie, S., Kobayshi, M., Sato, T., \& Kurihara, N. (2016). Associations between children's food preferences and food habits towards healthy eating in Japanese children. Journal of Child and Adolescent Behavior, 4, 1000292. https://doi.org/10.4172/2375-4494.1000292

Osera, T., Awai, M., Kobayshi, M., Tsutie, S., \& Kurihara, N. (2019). Self-rated health and Llifestyle/food habits in Japanese junior high school students. Global Journal of Health Science, 11(7), 80-89. https://doi.org/10.5539/gjhs.v11n7p80

Park, J. H., \& Lee, K. S. (2013). Self-rated health and its determinants in Japan and South Korea. Public Health. 127, 834-843. https://doi.org/10.1016/j.puhe.2012.12.012

Sanchez, A. (2017). The structural relationship between early nutrition, cognitive skills and non-cognitive skills in four developing countries. Economics and Human Biology, 27, 33-54. https://doi.org/10.1016/j.ehb.2017.04.001

Sharma, B., Nam, E. W., Kim, D., Yoon, Y. M., Kim, Y., \& Kim, H. Y. (2016). Role of gender, family, lifestyle and psychological factors in self-rated health among urban adolescents in Peru: a school-based cross-sectional survey. BMJ Open, 6, e010149. https://doi.org/10.1136/bmjopen-2015-010149

Silva, A. O., Diniz, P., Santos, M., Ritti-Dias, R.M., Farah, B. Q., Tassitano, R. M., \& Oliveira, L. (2018). Health self-perception and its association with physical activity and nutritional status in adolescents. Journal de Pediatria (Rio J), JEPD-683. https://doi.org/10.1016/j.jped.2018.05.007

Spexoto, M., Ferin, G., \& Campos, J. (2015). Pharmacology and biochemistry undergraduate students' concern for a healthy diet and nutrition knowledge. Nutricion Hospitalaria, 31, 1813-1823. https://doi.org/10.3305/nh.2015.31.4.8350

Tanaka, K. (1985). Ericsson's ego development stage theory. Kango-gaku zasshi, 49, 1103. https://doi.org/10.11477/mf.1661921204

Vigins, E. R., Wade, T. J., \& Seeley, J. (2002). Predictors of adolescent self-rated health. Analysis of the National Populaiton health survey. Canadian Journal of Public Health, 93, 193-197. 
http://dx.doi.org/10.17269/cjph.93.287

Warnoff, C., Lekander, M., Hemmingsson, T., Sorjonen, K., Melin, B., \& Andreasson, A. (2016). Is poor self-rated health associated with low-grade inflammation in 43110 late adolescent men of the general population? A cross-sectional study. BMJ Open, 6, e009440. https://doi.org/10.1136/bmjopen-2015-009440

Weber, C. S., Thayer, J. F., Rudat, M., Perschel, F. H., Buchholz, K., \& Deter, H. C. (2007). Emotional irritation before mental stress is associated with enhanced peripheral norepinephrine. Scandinavia Journal of Psychology, 48, 459-466. https://doi.org/10.1111/j.1467-9450.2007.00612.x

Wu, S., Wang, R., Zhao, Y., Ma, X., Wu, M., Yan, X., \& He, J. (2013). The relationship between self-rated health and objective health status: A population-based study. BMC Public Health, 13, 320. https://doi.org/10.1186/1471-2458-13-320

Zullig, K. J., Valois, R. F., Huebner, E. S., \& Drane, J. W. (2005). Adolescent health-related quality of life and perceived satisfaction with life. Quality of Life Research, 14, 1573-1584. https://doi.org/10.1007/s11136-004-7707-y

\section{Appendix A}

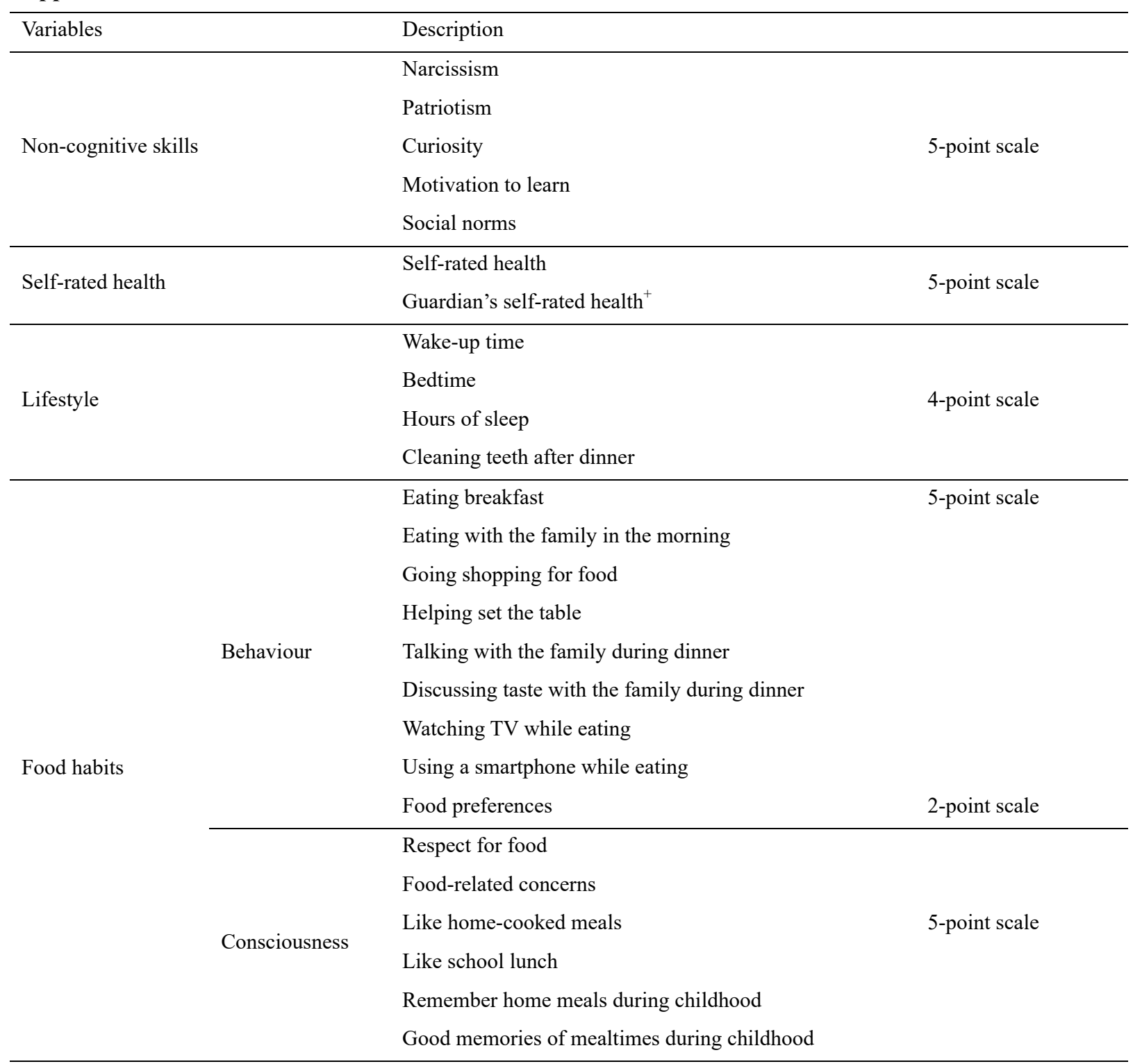




\section{No anorexia}

No irritation

Miscellaneous health issues*

No cephalalgia

5-point scale

No dizziness

No tiredness

Hours of sleep (between 7 and 8 hours)

Exercise habits

Breslow's health issues*

Eating breakfast every day

3-point scale

Not eating snacks

Maintaining ideal body weight

The earlier the time was, the higher the point the guardian selected.

* Only the 13-16 year age group.

${ }^{+}$Only the 6-12 year age group.

\section{Copyrights}

Copyright for this article is retained by the author(s), with first publication rights granted to the journal.

This is an open-access article distributed under the terms and conditions of the Creative Commons Attribution license (http://creativecommons.org/licenses/by/4.0/). 